\title{
Aspectos ultrassonográficos e citopatológicos das prostatopatias em 52 cães
}

\author{
Antonio Carlos Cunha Lacreta Junior ${ }^{1 *}$ \\ Márcio Botelho de Castro ${ }^{2}$ \\ Lúcia Ferreira da Rosa Sobreira ${ }^{3}$ \\ Júlio Carlos Canola ${ }^{4}$ \\ 'Departamento de Medicina Veterinária, Universidade Federal de Lavras \\ Campus Universitário, CEP 37200-000, Lavras - MG, Brasil \\ ${ }^{2}$ Laboratório de Patologia Veterinária, Faculdade de Agronomia e Veterinária \\ Universidade de Brasília, Avenida L4 Norte, CEP 70910-900, Brasília - DF, Brasil \\ ${ }^{3}$ Faculdade de Medicina Veterinária, Centro Universitário Moura Lacerda \\ Avenida Oscar de Moura Lacerda 1520, CEP 14076-510, Ribeirão Preto - SP, Brasil \\ ${ }^{4}$ Faculdade de Ciências Agrárias e Veterinárias, Universidade Estadual Paulista \\ Via de Acesso Prof. Paulo Donato Castellane, s/n, CEP 14884-900, Jaboticabal - SP, Brasil \\ *Autor para correspondência \\ lacreta@dmv.ufla.br
}

Submetido em 17/03/2011

Aceito para publicação em 09/10/2011

\section{Resumo}

Neste estudo foram avaliados 52 cães, machos, inteiros, de idades e raças diferentes, além de cães sem raça definida, apresentando sinais clínicos sugestivos de doença prostática. Todos os animais foram submetidos a exames ultrassonográfico e punção aspirativa da glândula prostática para avaliação citológica. A hiperplasia prostática benigna (HPB) foi a prostatopatia mais frequente, seguida pela hiperplasia prostática benigna cística, prostatite bacteriana, abscesso, cisto, adenocarcinoma, prostatite não bacteriana e cisto paraprostático. Depois dos cães sem raça definida, os da raça Poodle e Pastor alemão foram os que apresentaram maior frequência das afecções prostáticas. O exame ultrassonográfico permitiu a determinação das dimensões prostáticas, bem como a visibilização dos aspectos das enfermidades que acometem a glândula e foi efetivo na orientação da punção aspirativa. A avaliação citológica da glândula, principalmente quando associada às alterações das imagens ultrassonográficas, permitiu determinar o diagnóstico presuntivo da afecção.

Palavras-chave: Cães, Citologia aspirativa por agulha fina, Próstata, Prostatopatias, Ultrassom

\section{Abstract}

Ultrasonographic and cytopathologic aspects of prostate disease in 52 dogs. This study evaluated 52 dogs, which were male, intact, varied in age, of pure or mixed breed, with clinical signs suggestive of prostatic disease. Each individual underwent an ultrasound examination and fine-needle aspiration biopsy of the prostate gland for cytological evaluation. Benign prostatic hyperplasia (BPH) was the most frequent prostatic disease, followed by cystic benign prostatic hyperplasia, bacterial prostatitis, abscesses, cysts, adenocarcinoma, nonbacterial prostatitis and paraprostatic cysts. The highest frequencies of prostate disorder were found in mixed 
breeds, followed by poodles and German shepherds. Ultrasound examination allowed the determination of prostate size, as well as the visualization of the diseases affecting the gland, and was effective in guiding aspiration biopsy. The cytological evaluation of the gland, especially when associated with changes in ultrasound images, revealed the presumptive diagnosis of the condition.

Key words: Dogs, Fine-needle aspiration cytology, Prostate, Prostate diseases, Ultrasound

\section{Introdução}

Segundo Barsanti (1995) e Basinger et al. (1998), a próstata é a única glândula sexual anexa no cão, sendo relativamente grande, com estrutura densa e compacta, apresentando coloração amarelada (ELLENPORT, 1986). Possuí forma ovóide e septos irregulares na região dorsal, que se estendem até o tecido conjuntivo periuretral, dividindo-a em dois lobos (STABENFELDT; EDQVIST, 1988). Essa glândula é constituída por cápsula e estroma, ambos formados por tecido muscular liso, fibroblastos e colágeno, além de quantidade variável de tecido adiposo em sua porção ventral (BARSANTI, 1995).

O suprimento sanguíneo é realizado pela artéria prostática e a rede venosa é formada pelas veias prostática e uretral que desembocam na veia ilíaca interna (STEFANOV, 2004). A drenagem linfática da próstata é conduzida aos linfonodos ilíaco medial e hipogástrico (NYLAND; MATTOON, 2005).

Nos cães adultos, as células epiteliais predominam e o estroma ocupa $10 \%$ do órgão, decorrente do aumento dos níveis plasmáticos de testosterona (BARSANTI, 1995), ao contrário da fase pré-púbere onde o estroma é predominante (ELLENPORT, 1986). A função secretória da glândula parece estar associada ao transporte e a manutenção dos espermatozóides, não interferindo na fertilidade (BASINGER et al., 1998).

As enfermidades prostáticas mais observadas em cães são a hiperplasia-hipertrofia prostática benigna seguida pela prostatite bacteriana, cistos prostáticos, abscessos, metaplasia escamosa e neoplasias. Os sinais clínicos mais comuns dessas prostatopatias são os mesmos das doenças do trato urinário inferior, como disúria, estrangúria, hematúria e piúria (BARSANTI; FINCO, 1984; KRAWIEC; HEFLIN, 1992), além de distúrbios gastrointestinais, sinais de doenças sistêmicas e dificuldade locomotora (STRANDBERG; BERRY, 1985).

Dentre os métodos de diagnósticos usados para a detecção das doenças prostáticas no cão, citados em literatura e empregados na rotina clínica, estão os exames ultrassonográfico e a avaliação citológica com material obtido por meio de punção aspirativa por agulha fina (PAAF) guiada por ultrassom.

A utilidade clínica e segura da ultrassonografia torna essa técnica parte integrante da avaliação e tratamento da afecção prostática; é mais informativa e sensível que outros métodos de diagnóstico por imagem para a detecção de afecção prostática intraparenquimatosa, mas nenhum dos métodos existentes é específico para a investigação da etiologia (BASINGER et al., 1998). O aspecto ultrassonográfico normal da próstata no cão é muito variável quanto à forma e a textura, dependendo da idade, da condição sexual (castrado ou inteiro) e do histórico de ocorrência de doenças prostáticas anteriores (FEENEY et al., 1985). Assim como a forma e a textura, a ecogenicidade da próstata pode variar, sendo discretamente mais ecogênica que o baço (GREEN; HOMCO, 1996; MUZZI, 1998), apresentando uma área hiperecogênica central referente ao tecido fibroso periuretral (FEENEY et al., 1985; JOHNSTON et al., 1991; BARSANTI, 1995; JOHNSTON et al., 1995; MATTOON; NYLAND, 1995; GREEN; HOMCO, 1996; MUZZI, 1998; MEDEIROS JR; LUNARDELLI, 2003). Diversos estudos foram realizados procurandose determinar o tamanho da próstata no cão. Todavia, o tamanho varia de acordo com a idade, raça, peso corpóreo, maturidade sexual e influência hormonal (GREEN; HOMCO, 1996; RUEL et al., 1998; ATALAN et al., 1999b).

O exame ultrassonográfico tem grande utilidade na orientação da agulha durante o procedimento de PAAF, no auxílio do estabelecimento do diagnóstico presuntivo 
e no acompanhamento seriado do tratamento préestabelecido (BASINGER et al., 1998). Aultrassonografia também facilita a drenagem de lesões cavitárias (cistos e abscessos) (BOLAND et al., 2003; FROES et al., 2003).

A citologia é uma técnica popular que costuma produzir resultados mais rápidos do que o exame histopatológico (MUZZI, 1998). Além disso, permite a distinção de afecções prostáticas por meio da identificação de alteração no número, na população, na morfologia e nas características das células e de seus elementos (GADELHA, 2003). Células prostáticas normais são encontradas em grupos ou blocos, possuem núcleo redondo e citoplasma acidofílico (BURKHARD; MEYER, 1996). O núcleo, pequeno e pouco destacado (MUZZI, 1998), possui um padrão reticular ou pontilhado e o citoplasma é discretamente granular (ZINKL, 1999).

Os objetivos deste trabalho foram avaliar as alterações ultrassonográficas da próstata frente aos diferentes tipos de prostatopatias encontradas em cães, e descrever os aspectos citopatológicos dessas afecções.

\section{Material e Métodos}

Foram selecionados 52 cães machos, inteiros, de raça, idade e peso variados, levando-se em consideração a presença de alteração prostática, observada por meio da realização de exame ultrassonográfico.

Para realização do exame ultrassonográfico os cães foram posicionados primeiramente em decúbito dorsal sobre mesa de aço inox acolchoada, para realização da tricotomia do abdome e aplicação de gel acústico (Carbogel ${ }^{\circledR}$ - Gel acústico para ultrassom) na região parapeniana. Utilizou-se um aparelho de ultrassom (Fukuda Denshi FF-sonic UF-4500) com modo bidimensional em escala de cinza e transdutores microconvexo de $5,0 \mathrm{MHz}$ e linear de $7,5 \mathrm{MHz}$. A calibragem do equipamento foi ajustada para cada cão de acordo com as necessidades.

A avaliação ultrassonográfica da próstata consistiu na obtenção de informações sobre a localização, tamanho, forma, ecotextura e ecogenicidade, e avaliação da uretra quanto ao seu calibre, regularidade da superfície interna, estenoses e obstruções. Órgãos adjacentes à glândula, como bexiga urinária, linfonodos e vasos regionais também foram avaliados. Com exceção da avaliação do tamanho prostático, que foi realizada com base no estudo de Atalan et al. (1999a), todos os outros aspectos ultrassonográficos da glândula e da uretra foram avaliados por observação direta em tempo real, tomando como referência o aspecto normal do órgão proposto por Mattoon e Nyland (1995). As imagens ultrassonográficas da próstata obtidas nos planos sagital e transversal realizadas em decúbitos lateral esquerdo, direito e dorsal foram reproduzidas e arquivadas em papel termossensível (Sony UPP-110HA type IV), com auxílio de impressora térmica (Sony UP-890 MD).

Após a avaliação prostática, os animais foram pré-anestesiados utilizando-se diazepam (Diazepam ${ }^{\circledR}$ ampola de $2 \mathrm{ml}$ com $10 \mathrm{mg}$ - Laboratório Cristália) e clorpromazina (Amplictil ${ }^{\circledR}$ ampola de $5 \mathrm{ml}$ com $25 \mathrm{mg}$ - Laboratório Aventis) por via intramuscular, ambos na dose de $1 \mathrm{mg} / \mathrm{kg}$ de peso corpóreo e após dez minutos anestesiados com cetamina (Vetaset ${ }^{\circledR}$ frasco de $10 \mathrm{ml}$ com 1g - Laboratório Fort Dodge) por via intravenosa, na dose de $4 \mathrm{mg} / \mathrm{kg}$ de peso corpóreo.

Com os cães posicionados em decúbito dorsal e após antissepsia (Riodeine ${ }^{\circledR}$ degermante - Rioquímica) da região abdominal caudal, foi realizada a PAAF guiada por ultrassom, conforme a técnica proposta por Barr (1995), Muzzi (1998) e Penninck e Finn-Bodner (1998). Para a PAAF foi utilizado um citoaspirador (Citoaspirador de Valleri) acoplado a uma seringa de $20 \mathrm{~mL}$ (Seringa $\mathrm{BD}^{\circledR} 20 \mathrm{ml}$ ), agulhas hipodérmicas (Agulha hipodérmica BD ${ }^{\circledR} 22 \times 5,5$ e $25 \times 8,0$ ) ou espinais (Agulha espinal $\mathrm{BD}^{\circledR}$ Raqui $22 \mathrm{G}$ 2,5). A punção foi realizada em três regiões distintas do parênquima, e com o material obtido de cada local foram confeccionados, em média, dois esfregaços. Lesões cavitárias no parênquima prostático também foram aspiradas e esfregaços realizados a partir do sedimento obtido por meio de centrifugação (Centrífuga Excelsa Baby Mod. 208 N, Fanem), a 2.000G por cinco minutos. As lâminas foram coradas por método de Romanowisk (Panótico rápido) ou Giemsa e analisadas à microscopia de luz. A preparação das lâminas, incluindo a coloração e a avaliação citológica, seguiu o protocolo citado por 
Burkhard e Meyer (1996) e Zinkl (1999).

Thrall et al. (1985, apud MUZZI, 1998) demonstraram que houve correlação citológica das afecções prostáticas com os achados histopatológicos, radiográficos e microbiológicos em 22 dos 23 cães estudados (96\%). Com base nessa correlação, o diagnóstico presuntivo final foi confiado ao exame citológico.

Os resultados obtidos, por meio dos exames ultrassonográficos e citológicos, foram expressos mediante a distribuição de frequências e respectivas porcentagens, ilustrados sob a forma de tabelas.

As frequências foram analisadas mediante o teste qui-quadrado, e também comparadas por meio do teste da diferença de duas proporções, em alguns casos ao nível de $5 \%$ de significância $(\mathrm{p} \leq 0,05)$, em outros ao nível de $1 \%(\mathrm{p} \leq 0,01)$ como proposto por Spiegel (1967). Para as análises dos dados utilizou-se o programa estatístico de comparação SAS (Statistic Analysis System).

\section{Resultados e Discussão}

A distribuição da ocorrência das 74 prostatopatias nos 52 cães estudados, juntamente com seus respectivos pesos corpóreos $(\mathrm{kg})$, idades (anos) e raças, estão ilustrados na Tabela 1. O peso dos cães variou entre 4,2 e $63,1 \mathrm{~kg}$ (média de $20 \mathrm{~kg}$ ), assim como a faixa etária entre 3 e 15 anos (média de 9,9 anos).

TABELA 1: Distribuição das 74 prostatopatias em cães diagnosticadas por meio de exame ultrassonográfico e citológico, de acordo com raça, peso $(\mathrm{kg})$ e idade (anos).

\begin{tabular}{clccl}
\hline ANIMAL & \multicolumn{1}{c}{ PROSTATOPATIA } & PESO (kg) & IDADE (anos) & RAÇA \\
\hline 01 & PB / Abscesso & 15,3 & 15 & SRD \\
02 & HPB & 12,4 & 12 & SRD \\
03 & HPB & 10,2 & 11 & Fox Terrier \\
04 & HPBC / Cisto & 23,0 & 07 & Husky Siberiano \\
05 & HPB & 16,2 & 10 & SRD \\
06 & HPBC / Cisto & 4,2 & 06 & Pinscher \\
07 & PB / Abscesso & 14,3 & 12 & SRD \\
08 & HPB & 20,3 & 12 & SRD \\
09 & HPB / PB / Abscesso & 8,2 & 10 & Poodle \\
10 & HPBC & 7,5 & 13 & Poodle \\
11 & PI / Cisto & 11,4 & 10 & SRD \\
12 & HPB / PB & 6,3 & 08 & Poodle \\
13 & HPBC & 29,0 & 06 & Doberman \\
14 & HPB & 13,0 & 13 & SRD \\
15 & HPB & 15,0 & 10 & SRD \\
16 & HPB & 10,0 & 12 & SRD \\
17 & HPBC & 7,7 & 10 & Poodle \\
18 & HPB & 58,0 & 03 & Dogue Alemão \\
19 & HPB/Cisto Paraprostático & 32,0 & 08 & Pastor Alemão \\
20 & HPBC / Cisto & 6,5 & 07 & Poodle \\
21 & Adenocarcinoma & 42.6 & 12 & Pastor Alemão \\
22 & Adenocarcinoma & 16,8 & 07 & Cocker S. Inglês \\
23 & HPB & 7,5 & 06 & Dachshund \\
24 & HPB & 24,3 & 06 & Collie \\
25 & PB / Abscesso & 18,1 & 13 & SRD
\end{tabular}




\begin{tabular}{|c|c|c|c|c|}
\hline 26 & PB / Abscesso & 28,0 & 12 & Husky Siberiano \\
\hline 27 & HPB & 34,2 & 07 & Pastor Alemão \\
\hline 28 & НРВ & 5,0 & 08 & YorKshire Terrier \\
\hline 29 & HPBC & 4,2 & 12 & Yorkshire Terrier \\
\hline 30 & НРВ & 5,5 & 13 & Poodle \\
\hline 31 & НPBC & 44,3 & 03 & Rottweiler \\
\hline 32 & HPB & 6,1 & 08 & Dachshund \\
\hline 33 & HPBC / Cisto & 36,2 & 09 & Pastor Alemão \\
\hline 34 & НРВC & 33,5 & 13 & Weimaraner \\
\hline 35 & PB & 39,2 & 10 & Rottweiler \\
\hline 36 & НРB & 7,3 & 08 & Poodle \\
\hline 37 & НРBC & 11,3 & 13 & Fox Terrier \\
\hline 38 & НРB & 8,8 & 11 & Poodle \\
\hline 39 & HPBC / Cisto & 29,4 & 09 & Boxer \\
\hline 40 & HPB / PB & 34,2 & 12 & Pastor Alemão \\
\hline 41 & HPB & 7,3 & 10 & Poodle \\
\hline 42 & НРB & 15,2 & 07 & Mestiço \\
\hline 43 & HPB / PB / Abscesso & 63,1 & 09 & Fila Brasileiro \\
\hline 44 & НPB & 8,7 & 09 & Poodle \\
\hline 45 & HPBC / Cisto & 17,0 & 08 & SRD \\
\hline 46 & HPBC & 22,0 & 10 & SRD \\
\hline 47 & PB / Abscesso & 25,0 & 14 & SRD \\
\hline 48 & HPB / PB / Abscesso & 38,6 & 14 & Pastor Alemão \\
\hline 49 & НPB & 6,7 & 12 & Poodle \\
\hline 50 & $\mathrm{~PB} /$ Abscesso & 32,0 & 12 & Pastor Alemão \\
\hline 51 & НРB & 13,2 & 04 & Cocker S. Inglês \\
\hline \multirow[t]{2}{*}{52} & HPB & 37,1 & 10 & Pastor Alemão \\
\hline & Média & 20,05 & 9,92 & \\
\hline
\end{tabular}

$\mathrm{HPB}$, hiperplasia prostática benigna; HPBC, hiperplasia prostática cística; $\mathrm{PB}$, prostatite bacteriana; PI, prostatite não bacteriana, SRD, sem raça definida.

Os cães sem raça definida (SRD) foram os mais acometidos $(26,5 \%)$ pelas prostatopatias $(p \leq 0,05)$, seguido pelo Poodle (21,2\%), Pastor Alemão (15,4\%), Rottweiler, Husky Siberiano, Fox Terrier, Cocker Spaniel Inglês, Yorkshire Terrier, Dachshund $(3,8 \%)$ e Dogue Alemão, Doberman, Pinscher, Weimaraner, Boxer e Fila Brasileiro (1,9\%). Krawiec e Heflin (1992), Krawiec (1994) e Black et al. (1998) observaram em seus experimentos, a prevalência das doenças prostáticas em cães das raças Pastor Alemão e Doberman Pinscher, raças estas que configuraram $15,38 \%$ e $1,92 \%$ respectivamente nesse experimento. Contudo, os estudos foram realizados em regiões diferentes, o que poderia explicar a diferença de prevalência racial, além da predominância de animais sem raça definida na casuística hospitalar.

Foram encontradas as seguintes enfermidades: hiperplasia prostática benigna (HPB) e benigna cística (HPBC), prostatite bacteriana (PB), abscessos, cistos prostáticos e paraprostáticos, e adenocarcinoma. O diagnóstico citológico e as alterações ultrassonográficas estão descritos na Tabela 2. Alguns animais apresentaram mais de uma prostatopatia de forma concomitante. Foram observadas seis ocorrências de hiperplasia prostática benigna cística e cisto prostático, três de hiperplasia prostática benigna, prostatite bacteriana e abscesso prostático, uma de hiperplasia prostática 
TABELA 2: Diagnóstico citológico e alterações ultrassonográficas correspondentes as prostatopatias identificadas nos 52 cães.

Diagnóstico citológico
Hiperplasia prostática benigna
HPB)
Hiperplasia prostática benigna
cística (HPBC)

Prostatite bacteriana

Prostatite bacteriana supurativa (abscessos)

Prostatite não bacteriana

Adenocarcinoma

\section{Alterações ultrassonográficas}

Dimensões e ecogenicidade aumentadas, ecotextura grosseira de aspecto heterogêneo, podendo apresentar pequenas lesões cavitárias e dilatação uretral.

Dimensões aumentadas, ecogenicidade tendendo a hiperecóica, ecotextura grosseira de aspecto heterogêneo com presença de lesões cavitárias (cistos) de contorno regular, preenchidas por conteúdo anecogênico de aspecto homogêneo, podendo apresentar dilatação uretral secundária a estenose.

Dimensões e ecogenicidade aumentadas, ecotextura grosseira de aspecto heterogêneo, podendo apresentar pequenas lesões cavitárias e dilatação uretral com irregularidade da superfície interna.

Dimensões e ecogenicidade aumentadas, ecotextura grosseira de aspecto heterogêneo com presença de lesões cavitárias de contorno irregular (abscessos), preenchidas por conteúdo anecogênico de aspecto heterogêneo, podendo apresentar dilatação, estenose uretral, ou ambas, com irregularidade da superfície interna e coágulos intraluminais.

Dimensões e ecogenicidade aumentadas, ecotextura grosseira de aspecto heterogêneo.

Dimensões e ecogenicidade aumentadas, ecotextura grosseira de aspecto heterogêneo, podendo apresentar nódulos hiperecogênicos. benigna e cisto paraprostático, uma de hiperplasia prostática benigna e prostatite bacteriana, seis de prostatite bacteriana e abscessos prostáticos, e uma de prostatite não-bacteriana e cistos prostáticos. Esses achados corroboram com o observado por Gadelha (2003), demonstrando que embora caracterizadas como afecções de ocorrência individual, as prostatopatias podem ocorrer simultaneamente.

Os achados simultâneos da hiperplasia prostática benigna ou hiperplasia prostática benigna cística associada aos cistos prostáticos corroboram com Barsanti e Finco (1995), Muzzi et al. (1997), Vannucchi et al. (1997) e Muzzi, (1998), ao citarem que a hiperplasia prostática benigna inicia-se como hiperplasia glandular, que progride posteriormente para outra fase com morfologia mais complexa denominada de hiperplasia cística. Peter et al. (1995) e Vannucchi et al. (1997) referem que os cistos verdadeiros ou de retenção provavelmente estão relacionados com metaplasia escamosa e obstrução dos ductos secretórios da próstata com consequente acúmulo de fluidos e formações cavitárias no parênquima. Embora tenhamos observado ocorrências de cistos prostáticos associados a outras afecções, não o identificamos concomitante a metaplasia escamosa.

As prostatites bacterianas são geralmente causadas por infecção ascendente, a partir da uretra, embora seja possível haver contaminação oriunda de outro órgão urogenital, ou pela via hematógena (KRAWIEC; HELFLIN, 1992; BARSANTI, 1995; PETER et al., 1995). Em sua forma crônica, tem como complicação a abscedação prostática (DORFMAN; BARSANTI, 1995). Assim como observado por esses autores, neste trabalho todas as ocorrências de abscesso prostático estavam relacionadas com a prostatite bacteriana e em três animais também a HPBC.

Com base nas ocorrências simultâneas das prostatopatias nos animais avaliados, sugerimos a hipótese de que as prostatopatias são dinâmicas e as complicações inerentes a hiperplasia e hipertrofia da glândula predispõe a outras afecções.

A hiperplasia prostática benigna foi à doença prostática que afetou o maior número de cães, $53,84 \%$, seguida pela HPBC 26,92\%; PB 23,07\%; abscesso prostático $17,30 \%$; cisto prostático $13,46 \%$; adenocarcinoma prostático $3,84 \%$; prostatite não bacteriana $1,92 \%$ e cisto paraprostático 1,92\% (Tabela 3). A hiperplasia tem início no cão com um a dois anos de vida, e sua incidência aumenta com a idade. Mais de $80 \%$ dos cães com seis anos de idade apresentam evidências histológicas de hiperplasia prostática benigna e 95\% da incidência aos nove anos (BERRY et al., 1986). Segundo Jones et al. (2000), 100\% dos cães com mais de 6 anos 
de idade são acometidos pela hiperplasia prostática benigna, embora não seja raro encontrar evidência dessa patologia depois dos três anos de idade. A ocorrência da hiperplasia prostática benigna nesse estudo foi altamente significativa $(p=0,0001)$ em relação às outras doenças e ao número de cães acometidos, com $37,8 \%$ do total de 74 das ocorrências acometendo 53,84\% dos cães. A idade média dos cães desse experimento foi de 9,92 anos, justificando também o alto índice da doença.

Segundo Gadelha (2003), a incidência de neoplasias prostáticas em cães é baixa. Barsanti (1995) e Johnston et al. (1991) relatam uma ocorrência de 5\% e 0,2 a $0,6 \%$, respectivamente, entre todas as prostatopatias. Neste estudo, foi observada baixa incidência de neoplasia prostática no grupo estudado, apenas 3,85\% dos animais foram diagnosticados com adenocarcinoma. Dentre as neoplasias prostáticas observadas no cão, os adenocarcinomas são os mais frequentes e com maior incidência em cães apresentando em média 10 anos de idade (DI SANTIS et al., 2001). Em discordância a Bradbury et al. (2009), que demonstraram uma maior incidência de neoplasias prostáticas em cães castrados, os dois animais diagnosticados com adenocarcinoma eram inteiros.

TABELA 3: Ocorrências e frequências das prostatopatias $(n=74)$ em cães $(n=52)$ diagnosticadas por meio de exames ultrassonográfico e citológico de acordo com o número total de animais.

\begin{tabular}{lcc}
\multicolumn{1}{c}{ Prostatopatias } & Ocorrência & $\begin{array}{c}\text { Frequência } \\
\text { (\%) }\end{array}$ \\
\hline $\begin{array}{l}\text { Hiperplasia prostática } \\
\text { benigna }\end{array}$ & 28 & 53,84 \\
$\begin{array}{l}\text { Hiperplasia prostática } \\
\text { benigna cística }\end{array}$ & 14 & 26,92 \\
Prostatite bacteriana & 12 & 23,07 \\
Abscesso prostático & 09 & 17,30 \\
Cisto prostático & 07 & 13,46 \\
Adenocarcinoma & 02 & 3,84 \\
Prostatite não bacteriana & 01 & 1,92 \\
Cisto paraprostático & 01 & 1,92 \\
\hline
\end{tabular}

Por meio da ultrassonografia é possível avaliar o tamanho, margens e simetria da glândula (MEDEIROS JR; LUNARDELLI, 2003). Em todos os pacientes foi notado prostatomegalia ao exame ultrassonográfico; inclusive nos dois cães que apresentavam hérnia perineal e a próstata fazia parte do conteúdo herniário, foi possível visibilizar a próstata intrabdominal com suas dimensões aumentadas.

Assim como observado por Smith (2008), neste trabalho o exame ultrassonográfico constituiu uma excelente ferramenta, possibilitando determinar com precisão o contorno, a homogeneidade, a ecotextura e a presença de lesões cavitárias intra e extraparenquimais da próstata em todos os animais avaliados. Lesões cavitárias intraparenquimais foram evidenciadas por meio do ultrassom na HPB, na HPBC, na PB, nos abscessos, nos cistos prostáticos e na prostatite não bacteriana. Nos dois casos de adenocarcinoma prostático e no único caso de cisto paraprostático não foram evidenciadas estes tipos de lesão. Estas cavidades apresentaram contornos regulares ou irregulares, preenchidas por conteúdo anecogênico homogêneo ou heterogêneo (Figura 1 A-F). Agut et al. (2006) relataram uma fistula uretroretal associada a um abscesso prostático, esse evento não foi observado nos cães diagnosticados com essa última afecção. Houve apenas uma ocorrência de lesão cavitária extraparenquimal visibilizada por meio do ultrassom, coincidindo com o único caso diagnosticado com cisto paraprostático que também demonstrou manifestações HPB (Figura 2).

A textura pode ser uniforme nos casos de infecção crônica ou hiperplasia prostática benigna, e mista (com áreas focais hiperecogênicas e hipoecogênicas) nos casos de neoplasia, cistos e abscessos (JOHNSTON et al., 1995; PÉREZ-MARÍN et al., 2006). Ao contrário, no presente estudo, a textura da glândula na HPB e nas prostatites crônicas, encontrava-se heterogênea. Corroborando com Smith (2008), foram observados padrões heterogêneos da textura da próstata com áreas hiperecóicas e hipoecóicas nos casos de inflamação, hiperplasia e neoplasia. Nos cistos prostáticos e na HPBC, as cavidades estavam preenchidas por conteúdo anecóico e nos abscessos hipoecóicos. Não foram observadas mineralizações, embora Bradbury et al. (2009) as tenham encontrado na HPB, HPBC, PB, cisto paraprostático e neoplasias. 
FIGURA 1: Imagens ultrassonográficas em plano transversal (A, B e C) e longitudinal (D, E e F) da próstata de seis cães portadores de prostatopatias, ilustrando o aspecto de diferentes lesões intraparenquimais. A, B e C, hiperplasia prostática benigna cística com cistos (setas brancas); D, Prostatite não bacteriana com cisto (seta curva); E, prostatite bacteriana supurativa com formação de abscesso (ABS); F, hiperplasia prostática benigna com microcistos (Seta branca).

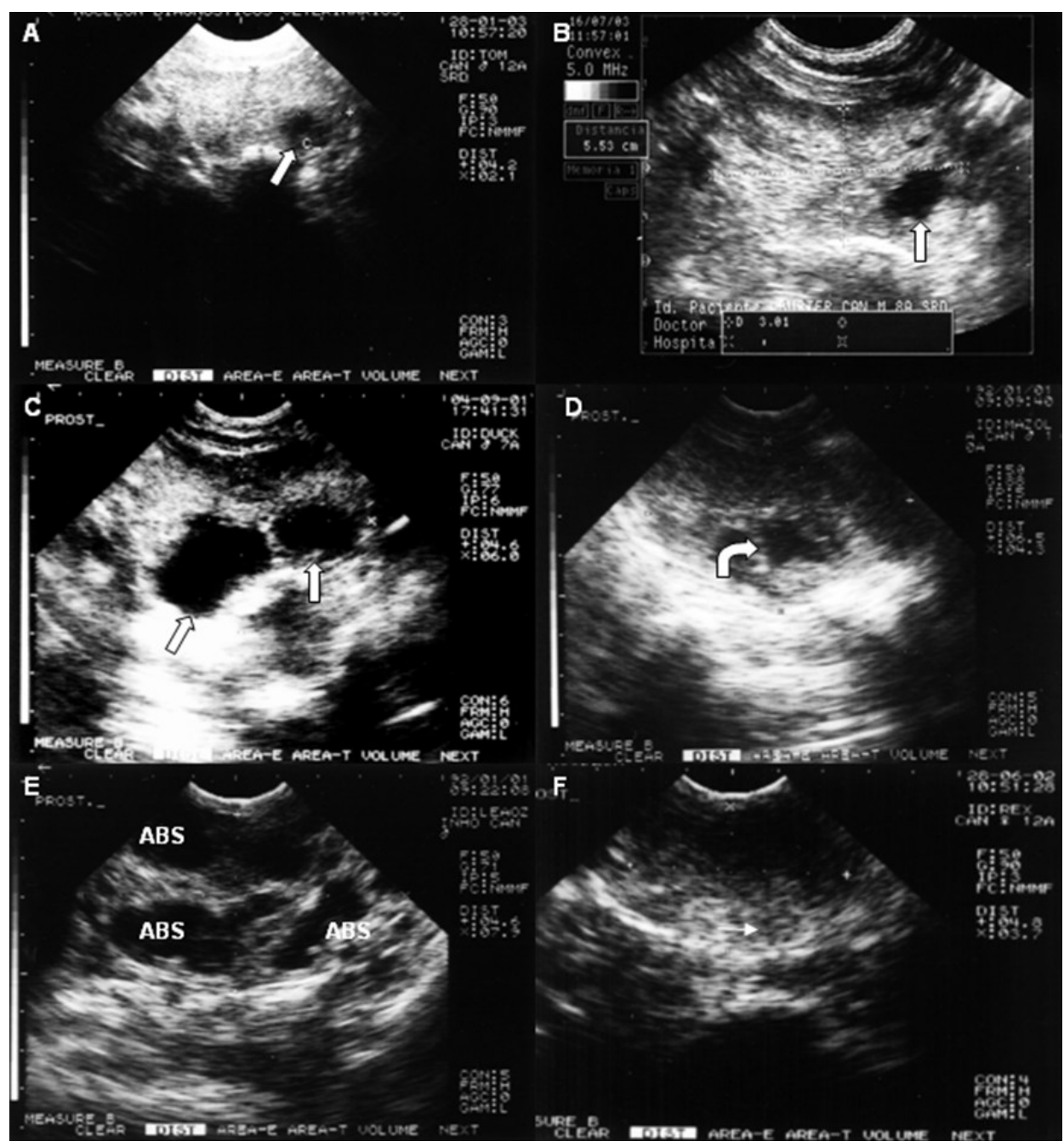

FIGURA 2: Imagens ultrassonográficas em plano longitudinal da próstata do animal 19 portador de cisto paraprostático. A, Formação cística paraprostática (cisto) preenchida por conteúdo heterogêneo predominantemente anecogênico deslocando a próstata (Prost.) ventralmente. B, Formação cística paraprostática (cisto) preenchida por conteúdo heterogêneo predominantemente hipo/anecogênico deslocando a bexiga $(\mathrm{BX})$ ventralmente.

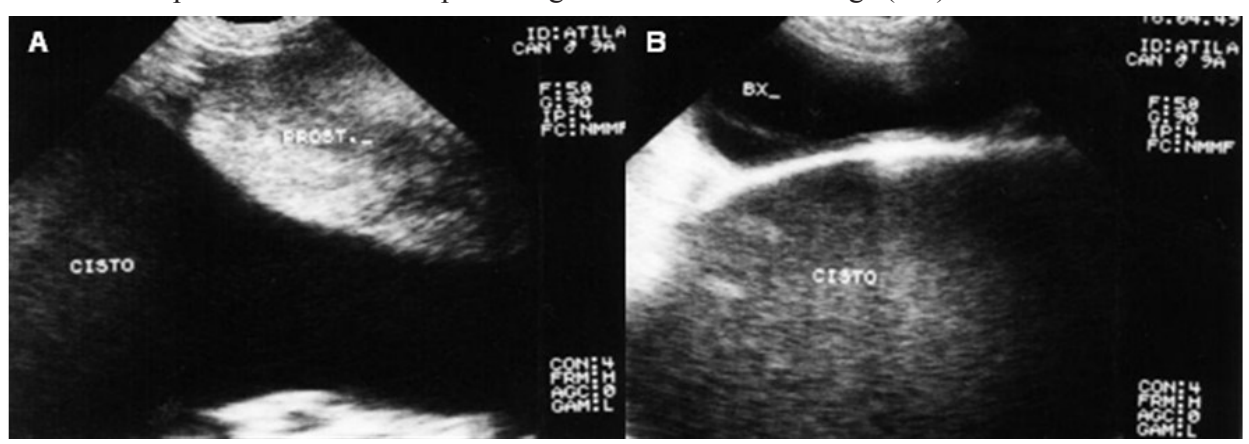


Alterações da ecogenicidade ultrassonográfica do parênquima ocorreram em todas as prostatopatias (Figura 3 A-F). Segundo Johnston et al. (1991), Green e Homco (1996) e Winter et al. (2006) a ecogenicidade da próstata pode estar aumentada nos casos de hiperplasia, prostatite crônica, fibrose e neoplasia. Igualmente a esses autores, observamos aumento de ecogenicidade nas mesmas afecções, e também na HPBC ao contrário dos mesmos. A diminuição de ecogenicidade foi observada nos casos de prostatites supurativas, abscessos e cistos, assim como observado por Johnston et al. (1991) e Green e Homco (1996). Perez-Marín et al. (2006) relataram parênquima glandular com ecogenicidade homogênea em um caso de HPB, não ocorrendo o mesmo no presente trabalho.

Alterações uretrais também foram observadas por meio da ultrassonografia, igualmente aos achados de Basinger et al. (1998). Apesar do método ultrassonográfico não ser o mais efetivo para avaliação da uretra, foi possível observar alterações uretrais em nove

FIGURA 3: Imagens ultrassonográficas em plano longitudinal da próstata de seis cães portadores de prostatopatias ilustrando diferentes alterações parênquimais da próstata caracterizadas por aspecto heterogêneo e ecogenicidade mista. A e B, adenocarcinoma prostático com áreas nodulares hiperecogêmicas (setas brancas); $\mathrm{C}$, hiperplasia prostática benigna com ecotextura grosseira e ecogenicidade mista; D, hiperplasia prostática benigna cística com presença de cistos intraprostáticos (c); E e F, Prostatite purulenta supurativa com formações de abscessos (setas curvas).

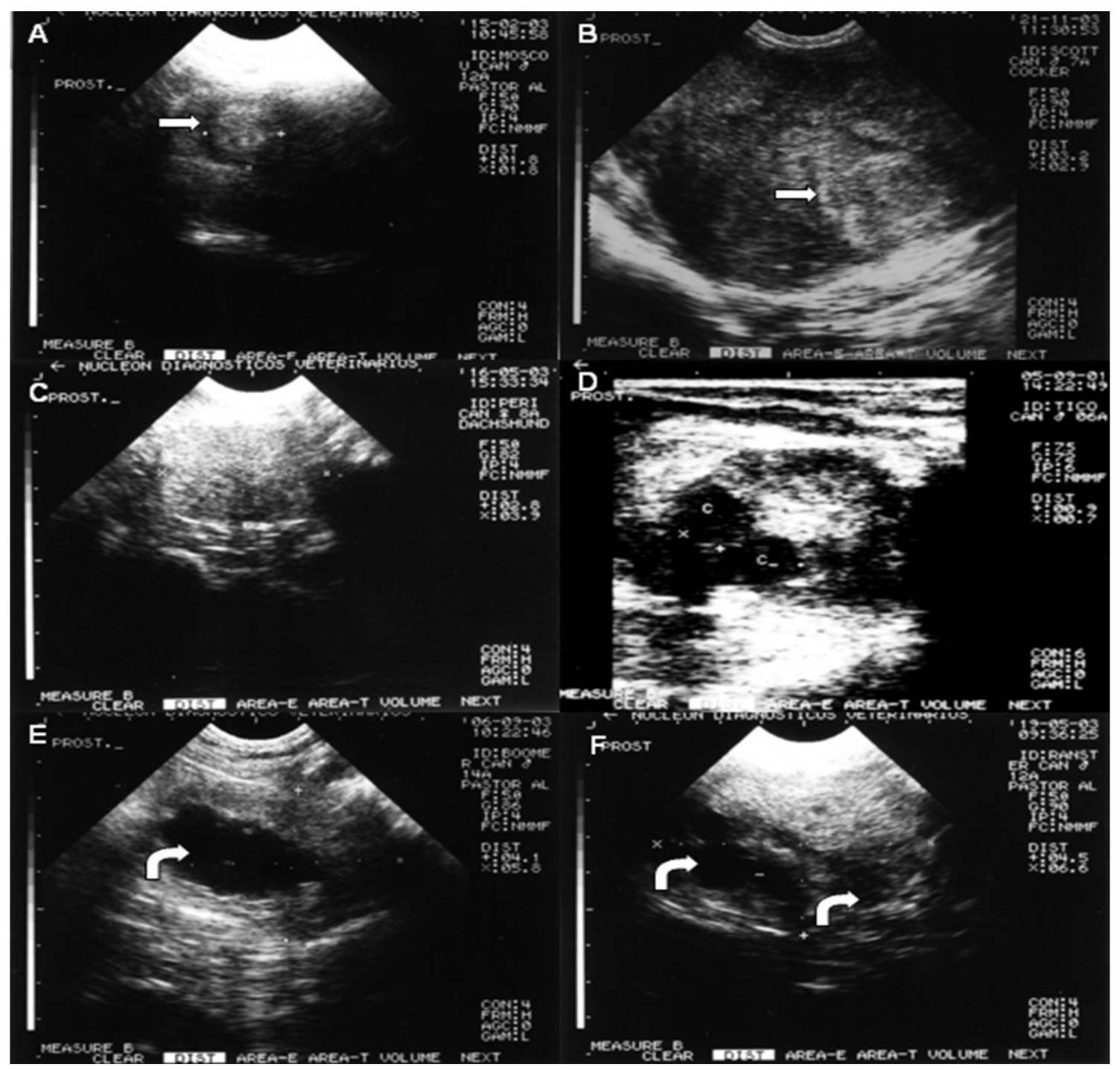


dos 52 animais. Dilatações uretrais foram observadas principalmente na HPB, HBPC e secundárias as estenoses, que por sua vez foram identificadas nos casos de formações cavitárias intra-parenquimais grandes (cistos e abscessos). Irregularidades de superfície interna e presença de coágulo intraluminal foram visibilizadas, principalmente nos abscessos e prostatites bacterianas (Figura 4 A-D).

Embora White (2000) tenha citado o aparecimento de metástases em linfonodos ilíacos, pélvicos e sublombares devido à característica invasiva das neoplasias, não foram evidenciadas alterações ultrassonográficas em linfonodos nos dois animais com neoplasia nem tão pouco nos outros 50 animais acometidos por outras afecções.

Ao exame citológico, os esfregaços dos animais com HPB demonstraram presença de blocos celulares epiteliais de tamanho variável dispostos em monocamadas, estando alguns com aspecto em "favo de mel". As células apresentaram citoplasma abundante, basofílico e ligeiramente granular, núcleos arredondados e nucléolos geralmente inaparente (Figura 5A), igualmente a observação feita por Burkhard e Meyer (1996) e Muzzi (1998), e intercaladas por hemácias e raros leucócitos, assim como citado por Zinkl (1999).

$\mathrm{Na}$ HPBC (Figuras 5B e 5C), os esfregaços demonstraram as mesmas alterações que na HPB, e o diagnóstico definitivo foi realizado juntamente com o exame ultrassonográfico, que neste caso revelou a presença de cistos prostáticos menores que $1,0 \mathrm{~cm}$ de diâmetro. Em um caso com HPBC (animal 46) não havia lesões cavitárias e o diagnóstico foi definido

FIGURA 4: Imagens ultrassonográficas em planos longitudinal (A, B e D) e transversal (C) da uretra prostática (UP) de cão, ilustrando diferentes alterações desta. A, prostatite bacteriana supurativa com abscesso (ABS), apresentando dilatação do segmento uretral cranial e compressão do caudal; B, prostatite bacteriana com presença de dilatação uretral e coágulo intra-luminal (seta branca); C, hiperplasia prostática benigna, com dilatação e irregularidade da superfície interna da uretra (seta curva); D, hiperplasia prostática benigna cística, apresentando dilatação total da uretra prostática.

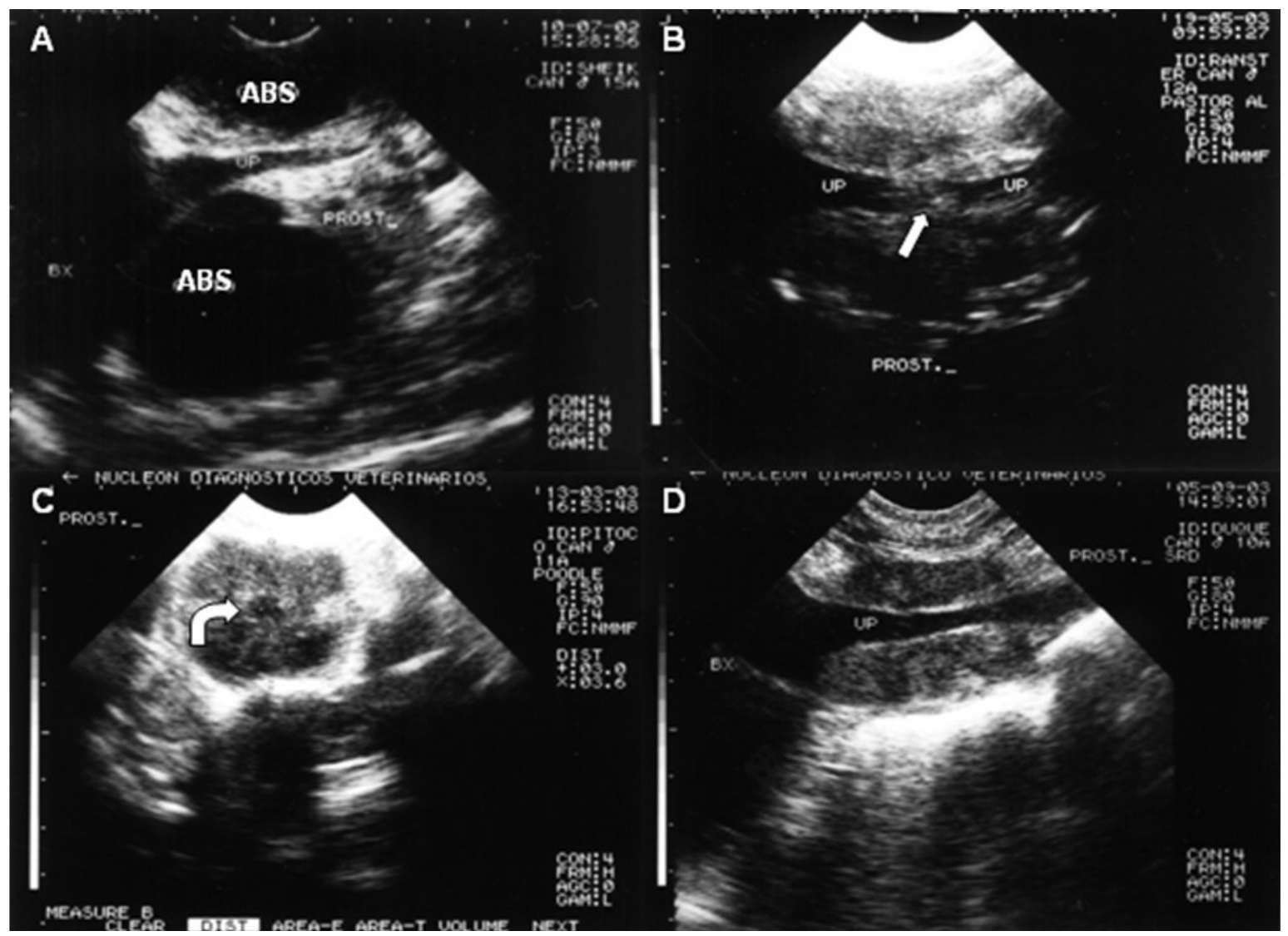


pelo grande número de macrófagos com citoplasma vacuolizado ao exame citológico (Figura 5B). Ambas as situações demonstram que não é totalmente seguro fazer o diagnóstico diferencial entre HPB e HPBC com base apenas em um dos métodos.

$\mathrm{Na} \mathrm{PB}$ havia células epiteliais sem alterações morfológicas significativas, porém ficou caracterizado processo inflamatório bacteriano pela presença maciça de neutrófilos íntegros e degenerados (demonstrando cariólise), raros macrófagos, hemácias, debris celulares e estruturas similares a bactérias (bastonetes) (Figura 5D), contudo sem apresentar células prostáticas, conforme citado por Muzzi (1998) e Zinkl (1999). Já os abscessos prostáticos foram caracterizados pela presença de achados característicos da PB juntamente com presença de lesão cavitária intraparenquimal ao exame ultrassonográfico.

Concordando com Zinkl (1999), o conteúdo dos cistos prostáticos ao exame citológico apresentouse hipocelular, com raros leucócitos e hemácias. O diagnóstico foi definido juntamente com a avaliação ultrassonográfica, por meio da qual foram visibilizadas lesões cavitárias preenchidas por conteúdo anecogênico, predominantemente homogêneo com mais de $1 \mathrm{~cm}$ de diâmetro.

No cisto paraprostático o conteúdo aspirado apresentou-se hipocelular e sem bactérias e o diagnóstico foi confirmado juntamente com os achados ultrassonográficos, assim como observado por Burkhard; Meyer (1996), Muzzi (1998) e Zinkl (1999).

No adenocarcinoma prostático os esfregaços apresentaram células com anisocitose, anisocariose, núcleos ovalados e nucléolos que variavam em formato e tamanho. A proporção núcleo-citoplasma estava aumentada e em alguns casos havia duplicação dos núcleos e nucléolos. Muzzi (1998) e Zinkl (1999)

FIGURA 5: Fotomicrografias dos achados citológicos obtidos por punção aspirativa das próstatas em quatro cães à microscopia de luz (400x). A, hiperplasia prostática benigna demonstrando blocos celulares epiteliais com células de citoplasma abundante (setas); $\mathrm{B}$ e $\mathrm{C}$, hiperplasia prostática benigna cística, notar células com citoplasma vacuolizado em B (seta) e células hiperplásicas em C; D, prostatite bacteriana (400x) com células epiteliais normais (seta fina), presença de neutrófilos (seta) e bactérias (seta curva).

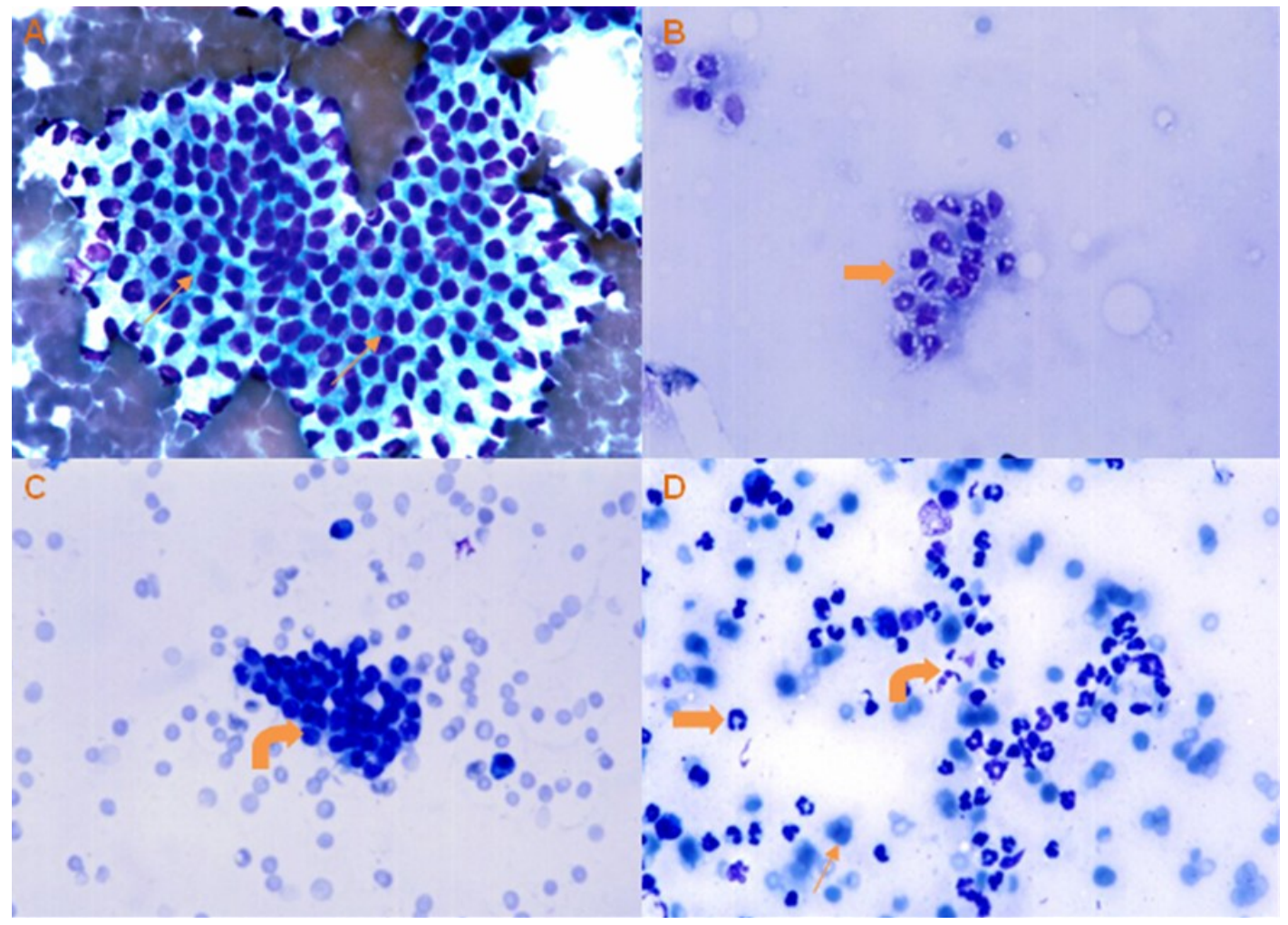


relataram aspectos citológicos semelhantes.

Na prostatite asséptica observaram-se leucócitos, hemácias, alguns macrófagos, debris celulares e células epiteliais sem alterações dignas de nota. $\mathrm{O}$ diagnóstico diferencial para PB foi dado com base na ausência de bactérias.

Apesar do diagnóstico presuntivo final das prostatopatias encontradas nos animais do presente trabalho, ter sido obtido com base nos resultados citológicos, é possível afirmar que a ultrassonografia isoladamente pode ser de grande utilidade. Lesões cavitárias sugerem hiperplasia prostática benigna cística, cistos, abscessos, bem como cistos paraprostáticos quando adjacentes à próstata. Prostatites agudas e assépticas são difíceis de serem diferenciadas da hiperplasia prostática benigna, assim como as neoplasias, que se apresentam sob diversos aspectos ultrassonográficos. Desta forma, conclui-se que o exame ultrassonográfico da próstata é de essencial importância para avaliação do parênquima prostático e para determinar a localização e o tamanho do órgão. Já a citologia mostrou-se efetiva, simples e rápida para o diagnóstico presuntivo da prostatopatia com restrições para seu uso isolado nos casos de HPBC, quando não se observa vacuolizações em macrófagos. A realização conjunta da ultrassonografia e da citologia a partir de material obtido por punção aspirativa mostrou-se um excelente protocolo para determinação e diferenciação da doença prostática em cães.

\section{Referências}

AGUT, A.; LUCAS, X.; CASTRO, A.; DE MEMBIELA, F.; SOLER, M.; BELDA, E. A urethrorectal fistula due to prostatic abscess associated with urolithiasis in a dog. Reproduction in Domestic Animals, Linköping, v. 4, p. 247-250, 2006.

ATALAN, G.; BARR, F. J.; HOLT, P. E. Comparison of ultrasonographic and radiographic

measurement of canine prostate dimensions. Veterinary Radiology and Ultrasound, Raleigh, v. 40, p. 408-412, 1999a.

ATALAN, G.; HOLT, P. E.; BARR, F. J. Ultrasonographic estimation of prostate size in normal dogs and relationship to bodyweight and age. Journal of Small Animal Practice, London, v. 40, p. 119-122, 1999 b.

BARR, F. Percutaneous biopsy of abdominal organs under ultrasound guidance. Journal of Small Animal Practice, London, v. 36, p. 105-113, 1995.

BARSANTI, J. A. Diseases of the prostate gland. In: OSBORNE,
C. A.; FINCO, D. R. (Ed.). Canine and feline nephrology and urology. Philadelphia: Williams and Wilkins, 1995. p. 726-755.

BARSANTI, J. A.; FINCO, D. R. Evaluation of thechniques for diagnosis of canine prostatic diseases. Journal of the American Veterinary Medical Association, Schaumburg, v. 185, p. 198-200, 1984.

BARSANTI, J.A.; FINCO, D. R. Prostatic diseases. In: ETTINGER, S. J.; FELDMAN, E.C. (Ed.). Textbook of veterinary internal medicine. v. 2. 4. ed. Philadelphia: W.B. Saunders Company, 1995. p. $1662-1685$.

BASINGER, R. R.; ROBINETTE, C. L.; HARDLE, E. M.; SPAULDING, K. A. Próstata. In: SLATTER, D. (Ed.). Manual de cirurgia de pequenos animais. 2 ed. São Paulo: Manole, 1998. p. 1607-1628.

BERRY, S. J.; STRNADBERG, J. D.; SAUNDERS, W. J.; COFFEY, D. S. Development of canine benign prostatic hyperplasia with age. Prostate, Baltimore, v. 9, p. 363-373, 1986.

BLACK, G. M.; LING, G. V.; NYLAND, T. G.; BAKER, T. Prevalence of prostatic cysts in adult, large-breed dogs. Journal of the American Animal Veterinary Association, Schaumburg, v. 34, p. 177-180, 1998.

BOLAND, L. E.; HARDIE, R. J.; GREGORY, S. P.; LAMB, C. R. Ultrasound-guided percutaneous drainage as the primary treatment for prostatic abscesses and cysts in dogs. Journal of the American Animal Veterinary Association, Schaumburg, v. 39, p. 151-159, 2003.

BRADBURY, C. A.; WESTROPP, J. L.; POLLARD, R. E. Relationship between prostatomegaly, prostatic mineralization, and cytologic diagnosis. Veterinary Radiology and Ultrasound, Raleigh, v. 50, p. 167-171, 2009.

BURKHARD, M. J.; MEYER, D. J. Invasive citology of internal organs: cytology of the thorax and abdomen. Veterinary Clinics of North America: Small Animal Practice, Philadelphia, v. 26, p. 1203-1222, 1996.

DI SANTIS, G. W.; AMORIN, R. L; BANDARRA, E. P. Aspectos clínicos e morfológicos das alterações prostáticas em cães: Uma revisão. Educação Continuada CRMV-SP, São Paulo, v. 4, p. 4652,2001

DORFMAN, M.; BARSANTI, J. A. Diaseases of canine prostate gland. Compedium on Continuing Education of the Practicing Veterinarian, Princeton, v. 17, n. 6. p. 791-810, 1995.

ELLENPORT, C. R. Aparelho urogenital do carnívoro. In: GETTY, R. (Ed.). Anatomia dos animais domésticos. Cap. 53. 5. ed, Rio de Janeiro: Editora Guanabara, 1986. p. 1481-1493.

FEENEY, D. A.; JOHNSTON, G. R.; KLAUSNER, J. S. Twodimensional, gray-scale ultrasonography. Applications in canine prostatic disease. Veterinary Clinics of North America: Small Animal Practice, Philadelphia, v. 15, p. 1159-1176, 1985.

FROES, T. R.; GONZALES, J. R. M.; KANAYMA, L. M.; JORGE, R. C.; IWASAKI, M. Ultra-sonografia intervencionista: Drenagem percutânea de lesões cavitárias e cistos prostáticos em cães. Clínica Veterinária, São Paulo, v. 47, p. 34-40, 2003.

GADELHA, C. R. F. Avaliação da próstata canina por palpação retal, ultra-sonografia, citologia por punção aspirativa, cultivo bacteriano e dosagem de fosfatase ácida prostática no soro e no plasma seminal. 2003. 60 f. Dissertação (Mestrado em Cirurgia 
Veterinária) - Universidade Estadual Paulista, Jaboticabal, 2003.

GREEN, R. W.; HOMCO, L. D. Prostate gland. In: GREEN, R.W. (Ed.). Small Animal Ultrasound. Philadelphia: Lippincott-Raven, 1996. p. 237-250.

JOHNSTON, G. R; FEENEY, D. A.; RIVERS, B.; WALTER, P. A. Diagnostic imaging of the male canine reproductive organs Methods and limitations. Veterinary Clinics of North America: Small Animal Practice, Philadelphia, v. 21, p. 553-589, 1991.

JOHNSTON, G. R.; WALTER, P. A.; FEENEY, D. A. Diagnostic imaging of the urinary tract, In: OSBORNE, C. A.; FINCO, D. R. Canine and feline nephrology and urology. Philadelphia: Williams and Wilkins, 1995. p. 726-755.

JONES, T. C.; HUNT, R. D., KING, N. W. Sistema Genital. In: JONES, T. C.; HUNT, R. D., KING, N. W. (Ed.). Patologia veterinária. 6 ed. São Paulo: Manole, 2000. p. 1237-1239.

KRAWIEC, D. R. Canine prostate disease. Journal of the American Animal Veterinary Association, Schaumburg, v. 204, p. 1561-1564, 1994.

KRAWIEC, D. R.; HEFLIN, D. Study of prostatic disease in dogs: 177 cases (1981-1986). Journal of the American Animal Veterinary Association, Schaumburg, v. 200, p. 1119-1122, 1992.

MATTOON, J. S.; NYLAND, T. G. Ultrasonography of the genital system. In: NYLAND, T. G.; MATTOON, J. S. (Ed.). Veterinary diagnostic ultrasound. Philadelphia: W. B. Saunders, 1995. p. 141-164.

MATTOON, J. S.; NYLAND, T. G. Próstata e testículos. In: NYLAND, T. G.; MATTOON, J. S. (Ed.). Ultra-som diagnostic em pequenos animais. 2. ed. São Paulo: Roca, 2005. p. 255-272.

MEDEIROS JR., L. C.; LUNARDELLI, F. Avaliação ultrassonográfica das patologias prostáticas em cães: aspectos e diagnóstico. Nosso Clínico, São Paulo, v. 36, p. 22-30, 2003.

MUZZI, L. A. Próstata do cão: Aspectos clínicos, radiográficos, ultrassonográficos e citológicos das afecções. 1998. $75 \mathrm{f}$. Dissertação (Mestrado em Medicina Veterinária) - Universidade Federal de Minas Gerais, Belo Horizonte, 1998.

MUZZI, L. A. L; MUZZI, R. A. L.; ARAÚJO, R. B. Ultrasonografia da próstata em cães. Clínica Veterinária, São Paulo, v. 2, n. 11, p. 19-22, 1997.

PENNINCK, D. G.; FINN-BODNER, S. T. Updates in interventional ultrasonography. Veterinary Clinics of North America: Small Animal Practice, Philadelphia, v. 28, p. 1017-1040, 1998.

PEREZ-MARÍN, C. C.; LÓPEZ, R.; DOMÍNGUEZ, J. M.; ZAFRA,
R. Clinical and pathological findings in testis, epididymis, deferens duct and prostate following vasectomy in a dog. Reproduction in Domestic Animals, Linköping, v. 41, p. 169-174, 2006.

PETER, A. T.; STEINER, J. M.; ADAMS, L. G. Diagnosis and medical management of prostate disease in the dog. Seminars in Veterinary Medicine and Surgery (Small Animal). Orlando, v. 10, n. 1, p. 35-42, 1995.

RUEL, Y.; BARTHEZ, P. Y.; MAILlES, A.; BEGON, D. Ultrasonographic evaluation of the prostate in healthy intact dogs. Veterinary Radiology and Ultrasound, Raleigh, v. 39, p. 212 216, 1998.

SMITH, J. Canine prostatic disease: A review of anatomy, pathology, diagnosis, and treatment. Theriogenology, Worburn, v. 70, p. 375-383, 2008.

STABENFELDT, G.H.; EDQUVIST, L.E. Processos reprodutivos no macho. In: SWENSON, M. J. (Ed.). Fisiologia dos animais domésticos. Cap. 50. 10 ed. Rio de Janeiro: Editora Guanabara, 1988. p. 719-730.

SPIEGEL, M. R. Estatística. Curitiba: Livro Técnico, 1967. 580 p. STEFANOV, M. Extraglandular and intraglandular vascularization of canine prostate. Microscopy Research and Technique, Malden, v. 63, p. 188-197, 2004.

STRANDBERG, J. D.; BERRY, S. J. 1985. The patology of prostatic hyperplasia in dog. In: RODGERS, C. H.; COFFEY, D. S.; CUNHA, G.; GRAYHACK, J. T.; HINMAN, F.; HORTON, R. (Ed.). Benign Prostatic Hyperplasia. Bethesda: National Institutes of Health, 1985. p. 109-117.

VANNUCCHI, C. I.; VENTURA, P. C. N.; SATZINGER, S.; SANTOS, S. E. C. Afecções prostáticas em cães: sinais clínicos, diagnóstico e tratamento. Clínica Veterinária, São Paulo, v. 2, n. 11, p. 37-42, 1997

WHITE, R. A. S. Prostatic surgery in the dog. Clinical Techniques in Small Animal Practice, Philadelphia, v. 15, n. 1, p. 46-51, 2000.

WINTER, M. D.; LOCKE, J. E.; PENNINCK, D. G. Imaging diagnosis: Urinary obstruction secondary to prostatic lymphoma in a young dog. Veterinary Radiology and Ultrasound, Raleigh, v. 47, p. 597-601, 2006.

ZINKL, J. G. Cytology of the male reproductive tract. In: COWELL, R. L.; TYLER, R. D.; MEINKOTH, J. M. (Ed.). Diagnostic cytology and hematology of the dog and cat. 2. ed. St Louis: Mosby, 1999. p. 230-234. 